\title{
COMPARATIVE STUDY OF DIFFERENT MODELS FOR CALCULATION OF DNI
}

\begin{abstract}
G. S. Lima,
A. O. Souza, and G. I. Medina T.

Universidade Federal do Rio Grande do Norte

Departamento de Engenharia Mecânica Laboratório de Sistemas Térmicos e Energias Alternativas - LSTEA, Campus Universitário Lagoa Nova 59078970, Natal, RN, Brasil

ABSTRACT

For prospecting or design of Concentrating Solar Power (CSP) systems it is necessary to know the distribution of the Direct Normal Irradiance (DNI) of the region. However, due to the recurring operational problems of measuring instruments, the use of mathematical models estimating the local DNI can be a very useful tool. The objective of this work is to construct a mathematical model that is used in the calculation of the DNI using experimental data provided by the Laboratory of Tropical Environmental Variables (LAVAT/INPE). This model was compared with other mathematical models already present in the literature. The consideration of clean-sky was used, that is, the effects of cloudiness, among others, were neglected.
\end{abstract} limagabriel@ufrn.edu.br adeilson_souza@live.com gmedinat@ct.ufrn.br

Received: June 14, 2018

Revised: July 16, 2018 Accepted: October 29, 2018
Keywords: concentrating solar power; direct normal irradiance; mathematical models; clear-sky

\section{NOMENCLATURE}

A altitude of the location, $\mathrm{km}$

$\mathrm{a}_{0} \quad$ parameter of the HLJ model

$\mathrm{b}_{0} \quad$ parameter of the HLJ model

$\mathrm{c}_{0} \quad$ parameter of the HLJ model

DNI Direct Normal Irradiance, $\mathrm{W} / \mathrm{m}^{2}$

$I_{s o} \quad$ extraterrestrial radiation, $\mathrm{W} / \mathrm{m}^{2}$

M parameter of the Eq. 13

MAPE Measure of Prediction Accuracy

MSE Mean Squared Error

$\mathrm{N} \quad$ parameter of the Eq. 13

$\mathrm{n} \quad$ number of data

O parameter of the Eq. 13

$\mathrm{P} \quad$ parameter of the Eq. 13

Q parameter of the Eq. 13

$\mathrm{P}_{\mathrm{a}}$ the local atmospheric pressure, $\mathrm{kPa}$

$\mathrm{P}_{\mathrm{a} 0} \quad$ pressure at sea level, $101.3 \mathrm{kPa}$

$\mathrm{r} \quad$ Pearson correlation coefficient

$\mathrm{x}$ theoretical parameter

$\bar{x} \quad$ average of $x$

y experimental parameter

$\bar{y} \quad$ average of $y$

\section{Greek symbols}

$\theta_{\mathrm{z}} \quad$ zenith angle

$\tau$ atmospheric attenuation/ transmittance

\section{Subscripts}

$\begin{array}{ll}\text { FR } & \text { Fu and Rich } \\ \text { HLJ } & \text { Hottel-Liu-Jordan } \\ \mathrm{i} & \text { sum index } \\ \mathrm{Ku} & \text { Kumar } \\ \mathrm{Mei} & \text { Meinel }\end{array}$

\section{INTRODUCTION}

The solar energy, unlike other renewable energy sources, cannot be used on a permanent basis. It has a regular distribution, excluding the local climatic conditions, being characterized by being an intermittent source and possessing spatial variability related to meteorological and astronomical factors (Pereira et al., 2017). According to Pereira et al. (2017), besides the potential of incidence of solar radiation, more specifically of Direct Normal Irradiance (DNI), it is necessary to know how the variation of distribution of this resource happens to be able to develop projects safe and to take advantage of this source of energy properly.

The DNI is the main component of global irradiance used in solar concentrator projects (Blanc et al., 2014). Solar power concentrating systems are usually used in power generation and can generate between a few $\mathrm{kW}$ and up to $50 \mathrm{MW}$ (Desai et al., 2014). According to Desai et al. (2014), the main CSP systems are the parabolic cylindrical collectors (PCC), the linear Fresnel reflectors (LFR), the parabolic disk (PD) and the solar power tower (SPT).

To evaluate the feasibility of implementing CSP systems, it is necessary to know the distribution of the local DNI. Mathematical models or experimental 
methods can be used to estimate this DNI. The problem of the use of experimental methods is that the equipment used can suffer failures, wear that prevent the constant measurement of the DNI, besides having no predictive character since the measurement has utility only at the time it is made due to the variability of the distribution of the incident solar radiation. The mathematical models, although they are only approximations and often do not consider all the main parameters that interfere in the DNI distribution, can have a predictive character if validated by experimental data. This predictive power of the mathematical model can provide valuable information for study or design of CSP systems for a given region.

The objective of this work is to compare the mathematical models constructed from experimental data with the mathematical models already present in the literature. For this work, the clean-sky model was considered (Behar et al., 2015). Experimental data were extracted from the INPE (http://www.crn2.inpe.br/lavat/index.php?id=climatol ogica, access in Aug. 2017). The calculations are made to the city of Natal/Brazil.

\section{MATHEMATICAL MODELS}

\section{HLJ model}

The HLJ model is a combination of Hottel model for direct transmittance and Liu and Jordan model for diffuse transmittance (Duffie and Beckman, 2013). For this model the DNI is given by:

$$
\mathrm{DNI}_{\mathrm{HLJ}}=\tau_{\mathrm{DNI}} \cdot \mathrm{I}_{\mathrm{SO}} \cdot \cos \left(\theta_{\mathrm{z}}\right)
$$

The $\tau_{D N I}$ expressed by:

$$
\tau_{\mathrm{DNI}}=\mathrm{AHLJ}_{\mathrm{HL}}+\mathrm{B}_{\mathrm{HLJ}} \cdot \mathrm{e}^{-\frac{\mathrm{CHLJ}}{\cos (\theta z)}}
$$

whose parameters are given by the equations:

$$
\begin{aligned}
& \mathrm{A}_{\text {HLJ }}=\mathrm{a}_{0} \cdot\left(0.4337-0.00821\left(6-\mathrm{A}^{2}\right)\right) \\
& \mathrm{B}_{\mathrm{HLJ}}=\mathrm{b}_{0} \cdot\left(0.5055-0.00595\left(6.5-\mathrm{A}^{2}\right)\right) \\
& \mathrm{CHLJ}_{\mathrm{H}}=\mathrm{c}_{0} \cdot\left(0.2711-0.01858\left(2.5-\mathrm{A}^{2}\right)\right)
\end{aligned}
$$

The values of $a_{0}, b_{0}$ e $c_{0}$ are of $0.95,0.98$ e 1.02 respectively, considering a tropical climate (Duffie and Beckman, 2013).

\section{Kumar model}

This model is described by the equation below (Behar et al., 2015):

$$
\mathrm{DNI}_{\text {кu }}=0.56 \mathrm{I}_{\text {so }}\left(\mathrm{e}^{-0.65 \mathrm{mKu}}+\mathrm{e}^{-0.095 \mathrm{mKu}}\right) \cdot \cos \left(\theta_{\mathrm{z}}\right)
$$

The air mass used in the equation is given by:

$$
\mathrm{m}_{\mathrm{Ku}}=\frac{\mathrm{Pa}}{\mathrm{Pa} 0} \cdot\left(1229+\left(614 \cos \theta_{\mathrm{z}}\right)^{0.5}-614 \cos \theta_{\mathrm{z}}\right)
$$

\section{Fu and Rich model}

This model depends only on the zenith angle and altitude of the spot (Behar et al., 2015):

$$
\mathrm{DNI}_{\mathrm{FR}}=\mathrm{I}_{\mathrm{so}} \tau_{\mathrm{bulk}}^{\mathrm{mf}} \cdot \cos \left(\theta_{\mathrm{z}}\right)
$$

The term $\tau_{\text {bulk }}$ is adopted as 0.5 (Behar et al., 2015), and $\mathrm{m}_{\mathrm{f}}$ is the correction of the air mass given by:

$$
\mathrm{m}_{\mathrm{f}}=\frac{\mathrm{e}^{-0.00018 \mathrm{~A}-1.638 \times 10^{-9} \mathrm{~A}^{2}}}{\cos \left(\theta_{\mathrm{z}}\right)}
$$

\section{Daneshyar-Paltridge-Proctor model (DPP)}

This model depends only on the angle of zenith (Badescu, 1998):

$$
\mathrm{DNI}_{\mathrm{DPP}}=950.2\left(1-\mathrm{e}^{-0.075\left(90^{\circ}-\theta_{\mathrm{z}}\right)}\right) \cos \theta_{\mathrm{z}}
$$

\section{Meinel model}

This model depends on the air mass and the angle of zenith (Behar et al., 2015):

$$
\mathrm{DNI}_{\mathrm{Mei}}=\mathrm{I}_{\mathrm{so}} 0.7^{\mathrm{m}_{\mathrm{ar}}^{0.678}} \cos \theta_{\mathrm{z}}
$$

in which the mass of air in this case is calculated by:

$$
\mathrm{m}_{\mathrm{ar}}=\frac{1}{\cos \left(\theta_{\mathrm{z}}\right)}
$$

\section{Adjusting curves for local experimental data}

Using the data provided by INPE (2017) the Origin8 software was used to perform a curve fit of a set of DNI distributions separated by season. The separation was made by season due to the impact on the distribution of solar radiation on the earth face caused by the change of the Earth's inclination along the movement of translation around the Sun.

\section{RESULTS AND DISCUSSION}

\section{Experimental Model}

A model based on the experimental data was proposed. 


$$
\mathrm{DNI}=\left(\mathrm{M}+\mathrm{Nt}+\mathrm{Ot}^{2}\right) \cdot \mathrm{e}^{\mathrm{Pt}+\mathrm{Qt}^{2}}
$$

This model has five parameters that are modified based on the season. The proposed model is shown in Eq. (13) where $t$ is the hours of day.

The parameters for each season of the year are shown in Tab. 1.

Table 1. Parameters of the experimental model.

\begin{tabular}{|l|c|c|c|c|c|}
\hline Day & $\mathrm{M}$ & $\mathrm{N}$ & $\mathrm{O}$ & $\mathrm{P}$ & $\mathrm{Q}$ \\
\hline $16 / 01$ & -121.646 & 29.199 & -1.273 & 0.500 & -0.021 \\
\hline $19 / 04$ & -9.661 & 2.172 & -0.093 & 1.000 & -0.044 \\
\hline $01 / 07$ & -8.512 & 1.831 & -0.077 & 1.016 & -0.044 \\
\hline $20 / 10$ & -27.505 & 7.126 & -0.325 & 0.773 & -0.034 \\
\hline
\end{tabular}

The model proposed together with the models found in the literature are shown in Figures 1, 2, 3 and 4.

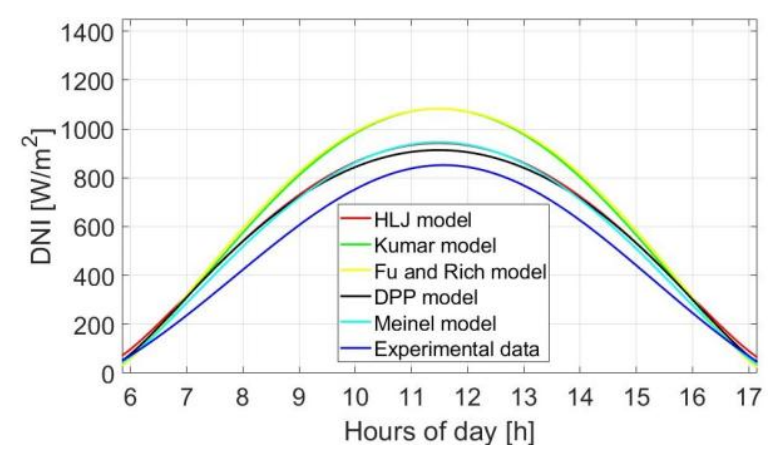

Figure 1. DNI along the day 16/01.

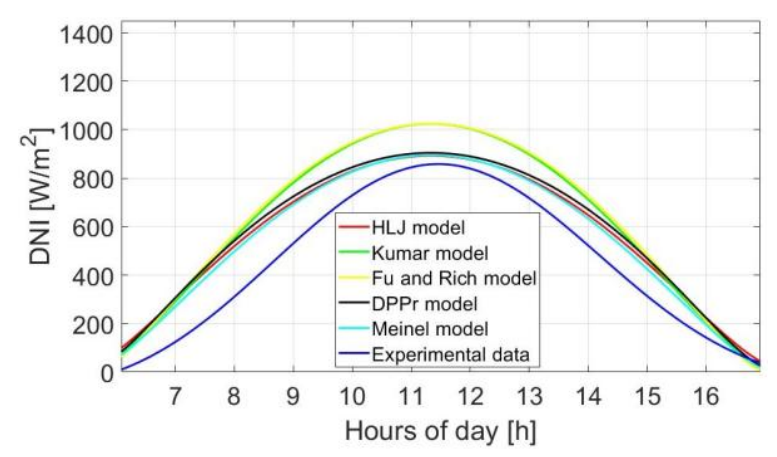

Figure 2. DNI along the day 19/04.

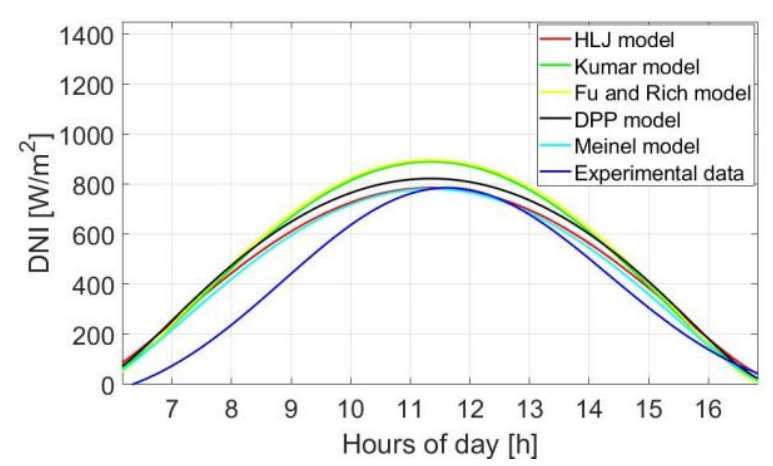

Figure 3. DNI along the day 01/07.

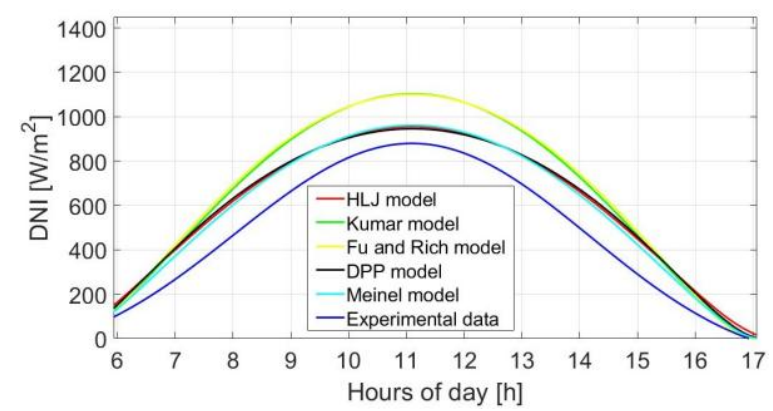

Figure 4. DNI along the day 20/10.

\section{Statistical Analysis}

To measure the relation between the experimental data and the data obtained by mathematical models in this paper, was used the Pearson correlation coefficient. The variables used were the irradiance obtained for experimentally model and obtained from mathematical models. A unit value of the coefficient implies a perfect linear relation between experimental and theoretical. It is expected then a value closer to 1 as possible.

$$
r=\frac{\sum\left(x_{i}-\bar{x}\right)\left(y_{i}-\bar{y}\right)}{\sqrt{\left(\sum\left(x_{i}-\bar{x}\right)^{2}\right)\left(\sum\left(y_{i}-\bar{y}\right)^{2}\right)}}
$$

where $x_{i}$ are the $i$-th irradiance calculated by mathematical models and $y_{i}$ are the $i$-th experimental irradiance. The $\overline{\mathrm{x}}$ and $\overline{\mathrm{y}}$ are the averages. The results are showed in the Tab. 2.

The Mean Squared Error (MSE) is a mathematical artifice used to measure the difference between predicted values of models and real values.

The lower its value, the better the model adjustment to the real data. It is used as optimization criterion in the selection of parameters and selection of models. The MSE is defined by:

$$
\mathrm{MSE}=\frac{1}{\mathrm{n}} \sum_{\mathrm{i}=1}^{\mathrm{n}}\left(\mathrm{x}_{\mathrm{i}}-\mathrm{y}_{\mathrm{i}}\right)^{2}
$$

in which the $x_{i}$ takes the role of predict values and $y_{i}$ of real or observed values. In this paper was used the MSE to select the mathematical model that best fits the experimental model. The results are showed in the Tab. 3.

Table 2. Pearson correlation coeficiente.

\begin{tabular}{|c|c|c|c|c|c|}
\hline Day & $\begin{array}{c}\text { HLJ } \\
\text { model }\end{array}$ & $\begin{array}{c}\text { Kumar } \\
\text { model }\end{array}$ & $\begin{array}{c}\text { Fu and } \\
\text { Rich } \\
\text { model }\end{array}$ & $\begin{array}{c}\text { DDP } \\
\text { model }\end{array}$ & $\begin{array}{c}\text { Meinel } \\
\text { model }\end{array}$ \\
\hline $16 / 01$ & 0.997 & 0.999 & 0.997 & 0.995 & 0.998 \\
\hline $19 / 04$ & 0.981 & 0.985 & 0.981 & 0.975 & 0.983 \\
\hline $01 / 07$ & 0.967 & 0.972 & 0.968 & 0.962 & 0.969 \\
\hline
\end{tabular}




\begin{tabular}{|l|l|l|l|l|l|}
\hline $20 / 10$ & 0.992 & 0.992 & 0.993 & 0.988 & 0.994 \\
\hline
\end{tabular}

The mean absolute percentage error (MAPE) is a measure of prediction accuracy of a forecasting method in statistics. It usually expresses accuracy as a percentage, and is defined by the equation:

$$
\text { MAPE }=\frac{1}{n} \sum_{\mathrm{i}=1}^{\mathrm{n}}\left|\frac{\mathrm{x}_{\mathrm{i}}-\mathrm{y}_{\mathrm{i}}}{\mathrm{y}_{\mathrm{i}}}\right|
$$

in which the $x_{i}$ takes the role of predict values and $y_{i}$ of real or observed values. In this paper was used the MAPE to select the mathematical model that best fits the experimental model. In the Tab. 4 is shown the results.

Table 3. Mean Squared Error.

\begin{tabular}{|c|c|c|c|c|c|}
\hline Day & $\begin{array}{c}\text { HLJ } \\
\text { model }\end{array}$ & $\begin{array}{c}\text { Kumar } \\
\text { model }\end{array}$ & $\begin{array}{c}\text { Fu and } \\
\text { Rich } \\
\text { model }\end{array}$ & $\begin{array}{c}\text { DDP } \\
\text { model }\end{array}$ & $\begin{array}{c}\text { Meinel } \\
\text { model }\end{array}$ \\
\hline $16 / 01$ & 8481.4 & 28475.9 & 31076.9 & 6478.1 & 6591.2 \\
\hline $19 / 04$ & 15438.9 & 32338.4 & 35578.6 & 19103.4 & 11925.3 \\
\hline $01 / 07$ & 11774.6 & 20159.1 & 23112.1 & 16989.7 & 8617.2 \\
\hline $20 / 10$ & 14653.3 & 37837.6 & 331949.4 & 331947.9 & 331949.4 \\
\hline
\end{tabular}

\section{Discussion}

All mathematical models presented are based on geographical parameters. Cloudiness in place is not considered, i.e, all the models are valid for clear-sky.

From the values the mean square error, it is noted that for each season of the year there is a distant model that is better suited to the experimental model. But analyzing the value of MAPE, it was observed that the Meinel model better fit the experimental model. The strong correlation between the data obtained from the experimental model and the mathematical model is observed for all models. For the summer the models Meinel and DDP presented the lowest MSE values. For fall and winter Meinel showed lower value. As for spring, HLJ presented lower MSE value.

Analyzing the value of MAPE, it is observed that the models present a large discrepancy in the average in relation to the observed values. Not fitting well to the experimental model in the average.

Table 4. Mean Absolute Percentage Error.

\begin{tabular}{|c|c|c|c|c|c|}
\hline Day & $\begin{array}{c}\text { HLJ } \\
\text { model } \\
(\%)\end{array}$ & $\begin{array}{c}\text { Kumar } \\
\text { model } \\
(\%)\end{array}$ & $\begin{array}{c}\text { Fu and } \\
\text { Rich model } \\
(\%)\end{array}$ & $\begin{array}{c}\text { DDP } \\
\text { model } \\
(\%)\end{array}$ & $\begin{array}{c}\text { Meinel } \\
\text { model } \\
(\%)\end{array}$ \\
\hline $16 / 01$ & 20.67 & 26.45 & 29.19 & 16.36 & 14.25 \\
\hline $19 / 04$ & 55.33 & 58.73 & 59.9 & 55.48 & 43.67 \\
\hline $01 / 07$ & 26.17 & 35.04 & 42.3 & 35.34 & 23.88 \\
\hline $20 / 10$ & 33 & 40.8 & 40.67 & 32.78 & 26.29 \\
\hline
\end{tabular}

\section{CONCLUSION}

In this work, a DNI calculation model was developed for the experimental data obtained by INPE (2017). A general model of equation was put with the parameters varying according to the seasons of the year.

The model obtained with the experimental data was compared with the calculation models present in the literature. The fact that this experimental model did not consider the cloudiness, among other factors, influenced the appearance of a lower DNI curve than the mathematical models put in this work.

Examining the statistical analysis made was observed a strong correlation between the model obtained with the experimental data and with the mathematical models of the literature used. But, by analyzing the MSE and MAPE values, some distinct facts were found: the Meinel model better fit the experimental model in terms of comparison using the MAPE, but using the MSE as a comparison it was observed that different mathematical models adjusted for different seasons. However, in general and observing the MAPE results, it was observed that the models tested in this work did not present good agreement with the proposed model obtained with the results of INPE (2017), affected by the sky clear condition.

Further study with the variation of the parameters of the proposed model during the year, besides the analysis with other models used in the literature, should be done to better estimate a more robust model for calculating DNI. It should be noted, however, that the proposed model, despite the discrepancy with the models in the literature, fits well with the experimental data in each season, thus serving as a utility for CSP systems projects.

\section{ACKNOWLEDGEMENTS}

The Laboratório de Sistemas Térmicos e Energias Alternativas team of the Universidade Federal do Rio Grande do Norte (LSTEA/UFRN) supported this work.

\section{REFERENCES}

Badescu, V., 1998, Verification of Some Very Simple Clear and Cloudy Sky Models to Evaluate Global Solar Irradianc, Solar Energy, Vol. 61, No. 4, pp. 251-264.

Behar, O., Khellaf, A., and Mohammedi, K., 2015, Comparison of Solar Radiation Models and their Validation Under Algerian Climate - The Case of Direct Irradiance, Energy Conversion and Management, Vol. 98, pp. 236-251.

Blanc, P., Espinar, B., Geuder, N., Gueymard, C., Meyer, R., and Pitz-Paal, R., 2014, Direct Normal Irradiance Related Definitions and Applications: the Circumsolar Issue, Solar Energy, Vol. 110, pp. 561577.

Desai, N. B., Kedare, S. B., and Bandyopadhyay, S., 2014, Optimization of Design 
Radiation for Concentrating Solar Thermal Power Plants without Storage, Solar Energy, Vol. 107, pp. 98-112.

Duffie, J. A., and Beckman, W. A., 2013, Solar Engineering of Thermal Processes Solar Engineering, 4th Edition, John Wiley \& Sons.

Pereira, E. B., Martins, F. R., Gonçalves, A. R., Costa, R. S., Lima, F. J. L., Rüther, R., Abreu, S. L., Tiepolo, G. M., Pereira, S. V., and Souza, J. F., 2017, Atlas Brasileiro Energia Solar, 2nd Edition, INPE. (in Portuguese) 